\title{
PROBLEMS OF THE BALANCE OF THE STATE BUDGET AND ECONOMIC GROWTH IN THE RUSSIAN FEDERATION
}

\author{
Alexander V. Velichko \\ Moscow Aviation Institute, branch "Vzlet", Akhtubinsk, Russian Federation
}

\begin{abstract}
The budget policy pursued in the Russian Federation in recent years has generated a number of negative trends, including a reduction in the resource potential of the budget system. A model of the budget mechanism for regulating socio-economic processes is considered. All blocks of the budget mechanism operate using various methods, that is, techniques, methods and conditions that determine the volume and movement of budget resources. The methods of calculating budget revenues, the procedure for making payments, the principles and conditions of budget financing, various sanctions are constituent parts of the budget mechanism. Structural changes in economy may be associated with the possibilities of influencing through specific types of budget revenues and expenditures on the economic interests of economic entities. Such approaches help to transform the types of budget revenues and expenditures into incentives for economic development and increase its efficiency. In all states, at various stages of historical development, taxes performed primarily a fiscal function centralizing a certain part of the gross domestic product (GDP) in the state budget in order to finance public spending. The article analyzes the main problems of improving the budget system of the Russian Federation, first of all, increasing the share of federal budget revenues (expenses) in GDP, as well as increasing the share of direct taxes in relation to indirect taxes during the period of economic growth. Economic growth must be considered in the context of solving the problem of huge receivables and payables between enterprises, which significantly exceed the annual consolidated budget of the Russian Federation and by the end of 2017, amounted to 40,258 and 44,481 billion rubles, respectively.
\end{abstract}

Key words: state budget, budget system, budget revenues, budget expenditures, budget mechanism, economic growth, gross domestic product.

Citation. Velichko A.V. Problems of the Balance of the State Budget and Economic Growth in the Russian Federation. Journal of Volgograd State University. Economics, 2020, vol. 22, no. 1, pp. 159-169. (in Russian). DOI: https://doi.org/10.15688/ek.jvolsu.2020.1.14

УДК 336.142 .3

Дата поступления статьи: 18.11.2019

ББК 65.26

Дата принятия статьи: 11.12.2019

\section{ПРОБЛЕМЫ СБАЛАНСИРОВАННОСТИ ГОСУДАРСТВЕННОГО БЮДЖЕТА И ЭКОНОМИЧЕСКОГО РОСТА В РОССИЙСКОЙ ФЕДЕРАЦИИ}

\author{
Александр Владимирович Величко \\ Филиал «Взлет» МАИ в г. Ахтубинске, г. Ахтубинск, Российская Федерация
}

\begin{abstract}
Аннотация. Бюджетная политика, проводимая в Российской Федерации в последние годы, породила ряд негативных тенденций, среди которых сокращение ресурсного потенциала бюджетной системы. В статье 으 рассмотрена модель бюджетного механизма регулирования социально-экономических процессов. Все блоฮิ ки бюджетного механизма функционируют с помощью различных методов, то есть приемов, способов и у условий, определяющих объем и движение бюджетных ресурсов. Способы исчисления бюджетных доходов, порядок внесения платежей, принципы и условия бюджетного финансирования, различного рода санкции представляют собой составные части бюджетного механизма. Структурные изменения в экономике могут быть связаны с возможностями влияния через конкретные виды доходов и расходов бюджета на экономичес๓ं кие интересы хозяйствующих субъектов. Такие подходы способствуют преобразованию видов доходов и (?) расходов бюджета в стимулы развития экономики и повышению ее эффективности. Во всех государствах на
\end{abstract}


различных этапах исторического развития налоги выполняли прежде всего фискальную функцию, централизацию определенной части валового внутреннего продукта (ВВП) в государственном бюджете с целью финансирования государственных расходов. В статье проанализированы основные проблемы совершенствования бюджетной системы РФ, прежде всего повышение удельного веса доходов (расходов) федерального бюджета в ВВП, а также повышение удельного веса прямых налогов по отношению к косвенным налогам в период роста экономики. Экономический рост необходимо рассматривать в контексте решения проблемы громадных дебиторской и кредиторской задолженностей между предприятиями, которые значительно превышают годовой консолидированный бюджет РФ и к концу 2017 г. составили 40258 и 44481 млрд руб. соответственно.

Ключевые слова: государственный бюджет, бюджетная система, доходы бюджета, расходы бюджета, бюджетный механизм, экономический рост, валовой внутренний продукт.

Цитирование. Величко А. В. Проблемы сбалансированности государственного бюджета и экономического роста в Российской Федерации // Вестник Волгоградского государственного университета. Экономика. -2020. - Т. 22, № 1. - C. 159-169. - DOI: https://doi.org/10.15688/ek.jvolsu.2020.1.14

\section{Введение}

Одним из ключевых факторов эффективности и действенности социально-экономической политики государства является рационально построенная и сбалансированная бюджетная система. Она обеспечивает перераспределение значительных финансовых ресурсов, и от направлений их использования в существенной мере зависит экономическое развитие государства и реальное благополучие граждан. Процесс формирования государственного бюджета - одна из самых важных сфер деятельности государства, которая проявляется в отношениях, регламентированных законодательством РФ. Основными целями государственного регулирования экономической системы любой страны являются экономический рост, стабилизация цен, увеличение занятости, развитие конкуренции. При этом развитие конкуренции способствует повышению эффективности производства и является фактором снижения цен, а экономический рост предполагает увеличение занятости и повышение жизненного уровня населения.

Бюджетная система РФ имеет федеративное устройство. Принципы единства и самостоятельности бюджетной системы закреплены в ст. 29 и 31 Бюджетного кодекса РФ. Под самостоятельностью понимается обособленное выделение федерального бюджета, бюджетов субъектов Федерации и местных бюджетов. Она обеспечивается наличием собственных доходных источников и правом определения направлений их использования. В законе проведено разграничение доходов и расходов между бюджетами. Однако оно не имеет завершенного вида, поскольку не во всех видах доходов установлены нормативы их распределения. Регулирование осуществляется более высоким уровнем органов власти и является, по сути, вмешательством в бюджетный процесс низшего уровня. Поэтому и самостоятельность бюджетов носит условный и ограниченный характер.

С точки зрения фискальной политики государства важным является не столько определение полноты и реальности принципов единства и самостоятельности, сколько согласованность этих принципов между собой. Объединение таких принципов ведет к тому, что бюджетная система становится плохо управляемой. Решения из центра входят в определенные противоречия с самостоятельностью каждого бюджета.

Рассматривая указанные принципы, следует отметить, что каждый из них имеет преимущества и недостатки. В условиях финансового кризиса централизованное руководство дает возможность концентрации ресурсов на наиболее важных направлениях. Жесткий контроль может способствовать обеспечению эффективности использования средств. Однако единство подрывает стимулы на местах к поиску и получению резервов роста доходов бюджета, к оптимизации расходов бюджета.

Принцип самостоятельности обеспечивает финансовую заинтересованность местных органов власти и управления и полноту ответственности за результаты формирования и использования бюджета. Местная инициатива создает предпосылки для роста ВВП в государстве. 
Однако возможности государства в перераспределении финансовых ресурсов ограничиваются в основном ФБ. Среди структурных элементов бюджетного процесса особое место и роль отводятся блоку определения отчислений в бюджет. Основным объектом перераспределения являются ВВП и НД, поэтому соотношение между этими показателями и ресурсами, которые перераспределяются через бюджет, дает представление о масштабах перераспределения и связанных с ним процессах.

\section{Поиск оптимальной}

\section{бюджетной политики в условиях сокращающейся ресурсной базы бюджетной системы}

Бюджетная политика, проводимая в РФ в последние годы, породила ряд негативных тенденций, среди которых сокращение ресурсного потенциала бюджетной системы. Во всех государствах на различных этапах исторического развития налоги выполняли прежде всего фискальную функцию, централизацию определенной части ВВП в государственном бюджете с целью финансирования государственных расходов. Критерий фискальной направленно- сти определяется тем, какая доля ВВП образуется с помощью налогов. Изменение динамики доли ВВП отражает степень вмешательства государства в экономику. Реальные статистические данные свидетельствуют о снижении уровня огосударствления ВВП в России. Так, в 2005 г. через ФБ перераспределялось (доходы) 27,3 \% ВВП; в 2006 г. - 25,7 \%, в 2007 г. $-24,9 \%$; в 2008 г. $-22,4 \%$; в 2009 г. $18,9 \%$; в 2010 г. $-16,8 \%$; в 2017 г. $-14,6 \%$ (табл. 1).

Поиск оптимальной бюджетной политики в условиях сокращающейся ресурсной базы бюджетной системы происходит в направлении сочетания двух противоречивых задач. С одной стороны - минимизации фискальной нагрузки на экономику с целью стимулирования экономической активности и потребительского спроса, с другой - максимального использования стимулирующего потенциала бюджетной политики. Например, в 2017 г. ресурсный потенциал федерального бюджета составлял 14,6 \% ВВП при дефиците ФБ 3,0 \% ВВП. Соответственно, доходный потенциал ФБ в 2017 г. был равен 11,6 \% ВВП. При сокращающейся ресурсной базе ФБ в 2004-2018 гг. правительству все труднее при-

Удельный вес доходов и расходов федерального бюджета РФ

\begin{tabular}{|c|c|c|c|c|c|}
\hline Год & $\begin{array}{c}\text { ВВП } \\
\text { (млрд руб.) }\end{array}$ & $\begin{array}{c}\text { Доходы } \\
\text { (млрд руб.) }\end{array}$ & $\begin{array}{c}\text { Расходы } \\
\text { (млрд руб.) }\end{array}$ & $\begin{array}{c}\text { Доходы } \\
\text { (\% ВВП) }\end{array}$ & $\begin{array}{c}\text { Расходы } \\
\text { (\% ВВП) }\end{array}$ \\
\hline 2001 & 7750,4 & 1593,9 & 1321,2 & 20,5 & 17,0 \\
\hline 2002 & 10950,2 & 2204,7 & 2054,1 & 20,1 & 18,7 \\
\hline 2003 & 13050,3 & 2586,1 & 2358,5 & 19,8 & 18,0 \\
\hline 2004 & 15300,6 & 3428,8 & 2698,8 & 22,4 & 17,6 \\
\hline 2005 & 18720,5 & 5127,2 & 3514,3 & 27,3 & 18,7 \\
\hline 2006 & 24380,3 & 6278,8 & 4284,8 & 25,7 & 17,5 \\
\hline 2007 & 31220,5 & 7781,1 & 5986,5 & 24,9 & 19,1 \\
\hline 2008 & 41276,8 & 9275,9 & 7570,8 & 22,4 & 18,3 \\
\hline 2009 & 38807,2 & 7337,7 & 9660,0 & 18,9 & 24,8 \\
\hline 2010 & 46308,5 & 7783,8 & 10212,4 & 16,8 & 22,0 \\
\hline 2011 & 55967,2 & 11366,2 & 10935,2 & 20,3 & 19,5 \\
\hline 2012 & 62218,4 & 12853,7 & 12890,8 & 20,6 & 20,7 \\
\hline 2013 & 66193,7 & 13019,9 & 13342,9 & 19,6 & 20,1 \\
\hline 2014 & 79200,6 & 14496,8 & 14830,6 & 20,3 & 20,7 \\
\hline 2015 & 83233,4 & 14923,9 & 15252,3 & 20,4 & 20,8 \\
\hline 2016 & 86044,6 & 15493,2 & 16416,2 & 18,6 & 19,1 \\
\hline 2017 & 92037,2 & 13488,0 & 1624,0 & 14,6 & 17,6 \\
\hline 2018 & 98120,6 & 17073,0 & 16591,0 & 17,4 & 16,5 \\
\hline 2019 (план) & 110938,8 & 19969,0 & 18037,0 & 18,9 & 17,0 \\
\hline 2020 (план) & 112327,7 & 20219,0 & 18994,0 & 18,3 & 17,2 \\
\hline 2021 (план) & 123400,0 & 20978,0 & 20026,0 & 17,7 & 16,9 \\
\hline
\end{tabular}

Примечание. Составлено автором по: [Удельный вес..., 2001-2018]. 
ходилось финансировать защищенные статьи бюджета.

То есть при существующей динамике снижения ресурсного потенциала бюджетной системы необходимо постоянно увеличивать дефицит ФБ. Поскольку правительство формально не собирается снижать государственные расходы, в конкретной экономической ситуации оно должно проводить дефицитный бюджет прежде всего для финансирования защищенных статей бюджета. Но, как видно из «Основных направлений бюджетной, налоговой, таможенной и тарифной политики на 2019 год и на плановый период 2020 и 2021 годов», правительство на ближайший плановый период планирует проводить бездефицитный бюджет. В этом документе также отмечено, что в «2019 году ожидается увеличение доходов федерального бюджета по отношению к ВВП, что связано с изменениями налогового законодательства (в первую очередь повышением ставки НДС с $18 \%$ до 20 \%)» [Основные направления...].

Как мы видим из «Основных направлений бюджетной, налоговой, таможенной и тарифной политики на 2019 год и на плановый период 2020 и 2021 годов», минимизации налоговой политики не произойдет и использовать стимулирующий потенциал бюджетной политики правительство не собирается. Отсюда можно сделать определенные выводы:

- во-первых, как видно из таблицы 1, планируемое увеличение доходов ФБ до 18,9 \% в 2019 г. - это такое «повышение», которое значительно ниже, чем в кризисные 2014-2015 гг., где уровень доходов был выше $20 \%$ ВВП;

- во-вторых, уровень расходов ФБ по отношению к ВВП планируется опустить до $17 \%$, что соответствует уровню конца 90-х годов;

- в-третьих, в период экономического роста соотношение между прямыми и косвенными налогами, на наш взгляд, должно быть в пользу прямых налогов.

\section{Модель бюджетного механизма регулирования \\ социально-экономических процессов}

Для успешного решения задач в области финансовой и экономической стабилизации необходимо проведение взвешенного бюджет- ного регулирования, прежде всего необходимо вносить коррективы в бюджетное законодательство, направленное на усиление действенности бюджетной политики и бюджетного механизма, его конструктивного влияния на реализацию стратегии экономического и социального развития страны в ближайшие годы.

Важнейшим инструментом регулирования бюджетной политики и социально-экономических процессов в государстве выступает бюджетный механизм, который является реальным воплощением бюджетной политики, отражает конкретную нацеленность бюджетных отношений на решение экономических и социальных задач. «С помощью бюджетного механизма можно практически использовать бюджет в качестве инструмента государственного регулирования экономики, стимулирования производственных и социальных процессов» [Финансы, 1993, с. 236].

Другие экономисты в структуре бюджетного механизма выделяют следующие элементы: «бюджетное планирование (прогнозирование), организацию бюджетного процесса, бюджетное регулирование и бюджетный контроль» [Ковалева, Барулин, 2005, с. 60]. «Бюджетный механизм, на наш взгляд, представляет собой комплекс специально разработанных государством форм организации бюджетных отношений, а также способов и методов, обеспечивающих перераспределение финансовых ресурсов между различными сферами общественной деятельности, отраслями экономики и регионами государства в интересах удовлетворения общегосударственных потребностей» [Величко, 1998, с. 32].

В зависимости от экономического содержания различных групп бюджетных отношений в структуре бюджетного механизма можно выделить четыре основных блока (см. рисунок).

Одной из составных частей бюджетного механизма выступают бюджетные нормы, нормативы и государственные социальные стандарты, которые сегодня далеки от современных экономических реалий и применяются без учета экономических возможностей государства. Речь идет, во-первых, о большом разрыве между минимальной заработной платой рядовых граждан и, например, заработной пла- 
той министров (чиновников) регионального и федерального уровней, которая исчисляется миллионами рублей в месяц. Во-вторых, необходимо разграничить заработную плату работников государственных предприятий (организаций) и негосударственных, то есть для первых ввести определенные ограничения, принятые на законодательном уровне. Например, руководитель государственного учреждения (предприятия) не может получать более 10 минимальных заработных плат в месяц.

До настоящего времени остается нератифицированным Порядок разработки и утвер- ждения государственных минимальных стандартов качества социальных услуг. Формирование государственных социальных стандартов и нормативов осуществляется по следующим принципам:

- законодательное установление важнейших государственных социальных стандартов и нормативов;

- дифференцированный подход при определении социальных нормативов, учитывая социально-демографическое развитие регионов;

- научная обоснованность норм потребления и обеспечения;

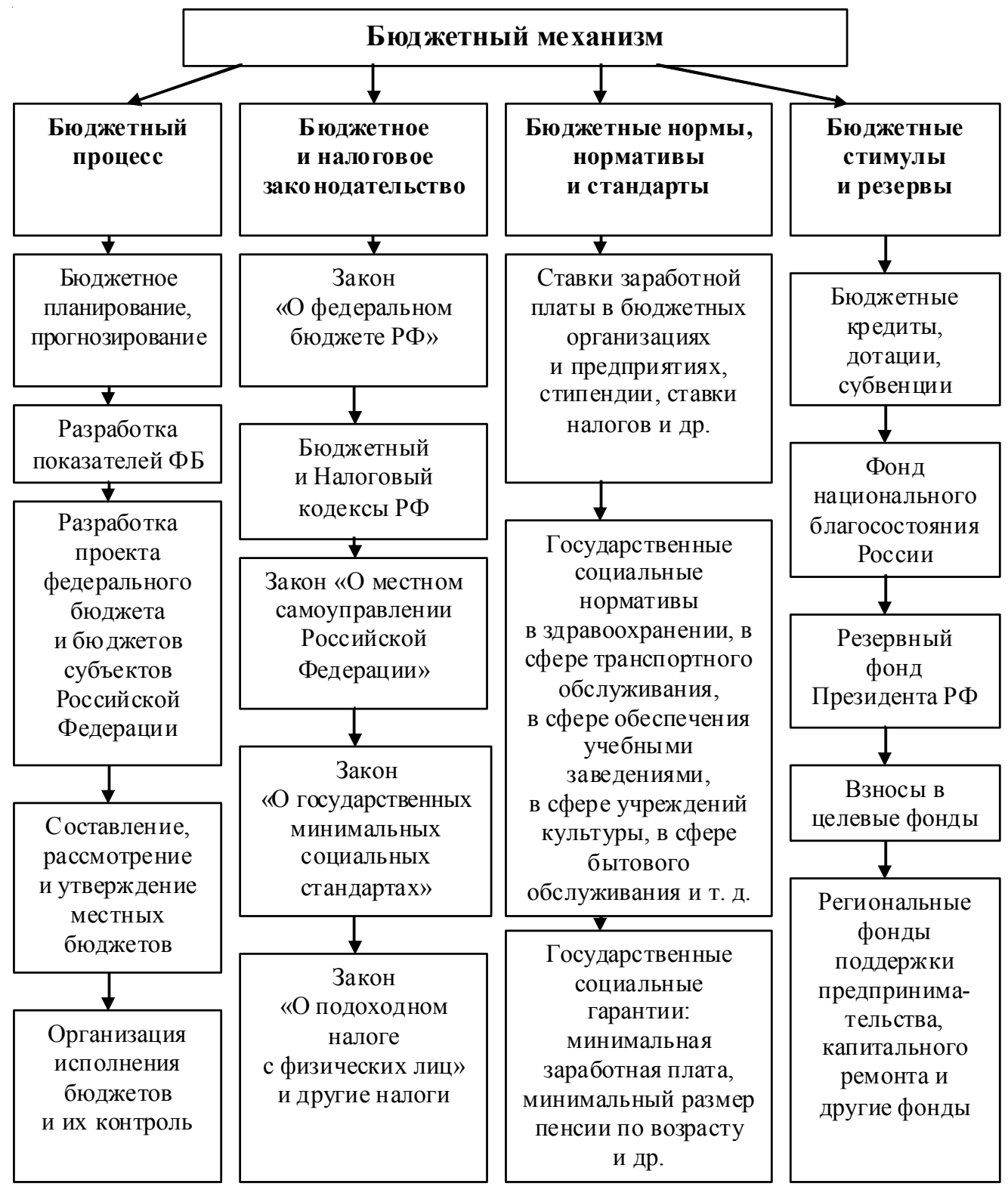

Рисунок. Модель бюджетного механизма

Примечание. Составлено автором по: [Величко, 1998, с. 33]. 
- гласность и общественный контроль при их определении и применении;

- учет требований норм международных договоров Российской Федерации в сфере социальной защиты и трудовых отношений.

Все блоки бюджетного механизма функционируют с помощью различных методов, то есть приемов, способов и условий, определяющих объем и движение бюджетных ресурсов. Способы исчисления бюджетных доходов, порядок внесения платежей, принципы и условия бюджетного финансирования, различного рода санкции представляют собой составные части бюджетного механизма. Структурные изменения в экономике могут быть связаны с возможностями влияния через конкретные виды доходов и расходов бюджета на экономические интересы хозяйствующих субъектов. Такие подходы способствуют преобразованию видов доходов и расходов бюджета в стимулы развития экономики, повышения ее эффективности. Целенаправленное использование всех элементов бюджетного механизма позволит как ускорять, так и замедлять социально-экономические процессы.

Существующая концепция реформирования межбюджетных отношений в России направлена на рассмотрение текущих бюджетных проблем и сохранение высокой централизации бюджетных решений. Самой большой статьей расходов консолидированного бюджета является «социальная политика» (табл. 2), которая должна быть направлена на «соци- альную защиту» населения. На данную статью ежегодно правительство выделяет 1012 трлн рублей, что в несколько раз превышает любую статью расходов бюджета. Это 30 \% всех расходов консолидированного бюджета РФ.

Однако проблема заключается в том, что большая часть населения страны эту защиту не ощущает. Понятие «социальная защита» содержит больше политического смысла, чем экономического. Защита в силу отсутствия возможностей может не состояться и остаться только намерением, которое не всегда зависит от воли защитника. В то же время каждому гражданину нужны социальноэкономические гарантии, закрепленные законодательно.

Социально-экономические гарантии нужны по нескольким основным направлениям.

Во-первых, государство должно гарантировать каждому гражданину, занятому трудовой деятельностью, нормальный уровень благосостояния через минимальный уровень заработной платы, ее индексацию, умеренные налоги и невмешательство в предпринимательскую деятельность.

Во-вторых, так называемые приоритетные потребности общества, удовлетворение которых государство не может доверить каждому гражданину самостоятельно. К ним относятся потребности в приобретении общего образования, воспитании детей и подростков, проведении культурно-просветительной работы, организации здравоохранения и развитии

Таблица 2

Расходы бюджетов бюджетной системы Российской Федерации по разделам классификации расходов

\begin{tabular}{|l|r|r|r|r|}
\hline \multicolumn{1}{|c|}{ Показатель, млрд руб. } & \multicolumn{1}{c|}{2010 г. } & \multicolumn{1}{c|}{2015 г. } & \multicolumn{1}{c|}{2016 г. } & \multicolumn{1}{c|}{2017 г. } \\
\hline Расходы, всего & 17616,7 & 29741,5 & 31323,7 & 32395,7 \\
\hline Общегосударственные вопросы & 1440,6 & 1848,2 & 1849,9 & 1952,6 \\
\hline Национальная оборона & 1279,6 & 3182,7 & 3777,6 & 2854,2 \\
\hline $\begin{array}{l}\text { Национальная безопасность и правоохра- } \\
\text { нительная деятельность }\end{array}$ & 1339,4 & 2072,2 & 2011,4 & 2034,1 \\
\hline Национальная экономика & 2323,3 & 3774,4 & 3889,8 & 4332,0 \\
\hline Жилищно-коммунальное хозяйство & 1071,4 & 979,9 & 992,6 & 1209,9 \\
\hline Образование & 1893,9 & 3034,6 & 3103,1 & 3264,2 \\
\hline Здравоохранение & 1708,8 & 2861,1 & 3124,4 & 2820,9 \\
\hline Социальная политика & 6235,9 & 10379,6 & 10800,6 & 12022,5 \\
\hline $\begin{array}{l}\text { Обслуживание государственного и муни- } \\
\text { ципального долга }\end{array}$ & 260,7 & 661,0 & 771,8 & 841,8 \\
\hline
\end{tabular}

Примечание. Составлено автором по: [Росстат, 2018]. 
физической культуры членов общества. Государство законодательно гарантирует удовлетворение названных потребностей за счет бюджета в минимально достаточных размерах и в форме бесплатных услуг.

Третье направление имеет своей целью выравнивание уровней жизни отдельных групп населения, недостаточная обеспеченность которых связана главным образом с причинами, не зависящими от их трудовых усилий.

Государство должно не формально осуществлять социальную защиту, которая при определенных условиях может и не состояться, а исходя из социальных стандартов и нормативов - оказывать социальные гарантии населению определенного качества. Поэтому, на наш взгляд, «политика», пусть даже социальная или экономическая, не должна выступать статьей расходов государственного бюджета.

Исторически сформировались три модели централизации финансовых ресурсов страны в бюджете: американская (либеральная) 25-30 \% ВВП, западноевропейская - 35-45 \% ВВП и скандинавских стран - 50-60 \% ВВП. «В России колебания доходов бюджета связаны главным образом не с деловым циклом, a с динамикой цен на нефть на мировом рынке. Соответственно, общий уровень бюджетных доходов нельзя считать стабильным во времени, размах их колебаний от года к году может достигать 5-7 \% ВВП в год, причем колебания доходов вследствие изменения внешнеэкономической ситуации и влияния биз- нес цикла могут не совпадать во времени» [Дробышевский, Синельников-Муратов, 2012, c. 8]. Конечно, уровень доходов бюджета определяется динамикой цен на нефть и газ, а удельный вес доходов и расходов к ВВП определяется просто желаниями правительства и той моделью, которую они себе выбрали.

Например, как видно из таблицы 3, с 2009 по 2018 г. удельный вес доходов консолидированного бюджета колебался на уровне 33-34\% ВВП, независимо от доходов бюджета, а удельный вес расходов снизился с 41,8 до 33,8 \% ВВП. Таким образом, мы видим отрицательную динамику в уровне расходов бюджета, независимо от кризиса или экономического роста. На наш взгляд, роль государства в распределительных процессах в периоды кризиса должна возрастать, а в периоды экономического роста, наоборот, ослабевать. Это относится и к налоговой политике. Несложно сделать вывод, что Россия медленно, но уверенно отошла от западноевропейской модели централизации финансовых ресурсов к американской (либеральной) модели, хотя на словах большинство ученых и политиков продолжают утверждать, что им больше нравится социально ориентированная рыночная экономика.

Для улучшения всей системы бюджетного планирования и прогнозирования необходима четкая система (схема) разработки его показателей на всех уровнях управления государством. Требует усовершенствования методика расчетов в первую очередь показате-

Таблииа 3

\section{Удельный вес доходов и расходов консолидированного бюджета РФ}

\begin{tabular}{|c|r|c|c|c|c|}
\hline Год & $\begin{array}{c}\text { ВВП, } \\
\text { млрд руб. }\end{array}$ & $\begin{array}{c}\text { Доходы, } \\
\text { млрд руб. }\end{array}$ & $\begin{array}{c}\text { Расходы, } \\
\text { млрд руб. }\end{array}$ & $\begin{array}{c}\text { Доходы } \\
\text { (\% ВВП) }\end{array}$ & $\begin{array}{c}\text { Расходы } \\
\text { (\% ВВП) }\end{array}$ \\
\hline 2009 & 38807,2 & 13599,1 & 16048,3 & 34,7 & 41,8 \\
\hline 2010 & 46308,5 & 16031,9 & 17616,7 & 33,4 & 39,1 \\
\hline 2011 & 55967,2 & 20855,4 & 19994,6 & 35,0 & 38,7 \\
\hline 2012 & 66926,9 & 23435,1 & 23174,7 & 35,0 & 34,6 \\
\hline 2013 & 71016,7 & 24442,7 & 25290,1 & 34,4 & 35,6 \\
\hline 2014 & 77945,1 & 26766,1 & 27611,7 & 34,3 & 35,4 \\
\hline 2015 & 80804,3 & 26922,0 & 29741,5 & 33,3 & 36,8 \\
\hline 2016 & 86149,6 & 28181,5 & 31323,6 & 32,7 & 36,3 \\
\hline 2017 & 92037,3 & 31046,6 & 32395,7 & 33,7 & 35,1 \\
\hline 2018 & 98120,6 & 34386,0 & 34216,0 & 34,0 & 33,8 \\
\hline 2019 план & 110938,8 & 38167,0 & 36472,0 & 36,1 & 34,5 \\
\hline 2020 план & 112327,7 & 39407,0 & 38307,0 & 35,6 & 34,6 \\
\hline 2021 план & 123400,0 & 41464,0 & 40582,0 & 35,0 & 34,3 \\
\hline
\end{tabular}

Примечание. Составлено автором по: [Росстат, 2018, с. 509]. 
лей ВВП и НД. Например, кризис в 20082009 гг. в бюджетной сфере, на наш взгляд, был усилен действиями денежных властей РФ. Правительство в течение пяти лет - с 2004 по 2008 г. - проводило бездефицитный федеральный бюджет. Доходы превышали расходы в среднем на $1500-1700$ млрд рублей (табл. 1). При таком избытке денежных ресурсов государство умудрялось недофинансировать некоторые законодательно закрепленные расходные статьи ФБ.

\section{Кризис неплатежей и проблема экономического роста}

В России фактически сформировался специфический сектор расчетов, который имеет свои пропорции обмена и свои условные цены, развивающиеся без учета динамики предложения национальных денег. Речь идет о значительных объемах взаимной задолженности предприятий, которые фактически свидетельствуют, что этот сектор, по крайней мере, не сворачивается. Дебиторская и кредиторская задолженности по всем субъектам хозяйствования (кроме субъектов малого предпринимательства) к концу 2017 г. соста- вили соответственно 40258 и 44481 млрд рублей. Удельный вес убыточных предприятий в течение последних 10 лет остается на стабильно высоком уровне - 30-32 \% (табл. 4). Таким образом, каждая из задолженностей в отдельности превышает годовой консолидированный бюджет РФ и составляет 50 \% ВВП.

Если мы рассмотрим консолидированный бюджет РФ в 2017 г., то налог на прибыль организаций составил 3 290,1 млрд руб., а НДС на товары, реализуемые на территории РФ, 3 070,2 млрд руб. плюс 2 067,4 млрд руб. на товары, которые были ввезены на территорию РФ [Росстат, 2018]. То есть совокупный НДС значительно превышает налог на прибыль. Появление экономического роста пока сопровождается углублением финансовых противоречий как между государством и экономическими агентами, так и между самими субъектами хозяйствования. Для характеристики экономического роста нужно пользоваться не только общеизвестными показателями и распространенными моделями, но и учитывать некоторые ее специфические черты. Задолженность по налогам и сборам в КБ РФ превышает 1 трлн руб., а по федеральным налогам и сборам - 760 млрд рублей [Росстат, 2018, с. 518].

Динамика задолженности организаций РФ

Таблица 4 (без субъектов малого предпринимательства)

\begin{tabular}{|c|c|c|c|}
\hline Год & $\begin{array}{c}\text { Кредиторская } \\
\text { задолженность } \\
\text { (млрд руб.) }\end{array}$ & $\begin{array}{c}\text { Дебиторская } \\
\text { задолженность } \\
\text { (млрд руб.) }\end{array}$ & $\begin{array}{c}\text { Удельный вес } \\
\text { убыточных } \\
\text { предприятий, \% }\end{array}$ \\
\hline 1999 & 2901 & 2000 & 40,8 \\
\hline 2000 & 3515 & 2451 & 39,8 \\
\hline 2001 & 4231 & 3211 & 37,9 \\
\hline 2002 & 4832 & 3663 & 43,5 \\
\hline 2003 & 5283 & 4139 & 43,0 \\
\hline 2004 & 5944 & 5174 & 38,1 \\
\hline 2005 & 6389 & 6331 & 36,4 \\
\hline 2006 & 7697 & 7871 & 32,5 \\
\hline 2007 & 10653 & 11061 & 25,5 \\
\hline 2008 & 13353 & 13783 & 28,3 \\
\hline 2009 & 14882 & 15442 & 32,0 \\
\hline 2010 & 17683 & 18004 & 29,9 \\
\hline 2011 & 20954 & 21797 & 30,0 \\
\hline 2012 & 23632 & 22867 & 29,1 \\
\hline 2013 & 27532 & 26264 & 31,0 \\
\hline 2014 & 33174 & 31014 & 33,0 \\
\hline 2015 & 38925 & 35736 & 32,6 \\
\hline 2016 & 42280 & 37053 & 29,5 \\
\hline 2017 & 44481 & 40258 & 26,3 \\
\hline
\end{tabular}

Примечание. Составлено автором по: [Росстат, 2018]. 
Во-первых, с такими показателями задолженности, как между предприятиями, так и в консолидированный бюджет, говорить об экономическом росте, по крайней мере, некорректно.

Во-вторых, государство планомерно и целенаправленно отказывается от регулирующей и стимулирующей функций налоговой системы, то есть в ближайшие годы наблюдается устойчивая тенденция к росту удельного веса НДС в доходной части бюджета. В прогнозных показателях на 2018 и 2021 гг. правительство прогнозирует увеличение данного налога с 3446 млрд руб. в 2018 г. до 4600 млрд руб. в 2021 году.

В период трансформационных преобразований ставка НДС, на наш взгляд, должна быть минимизирована и не превышать 1517 \%. Такое изменение налога будет способствовать расширению внутреннего потребления. Снижение ставки также повлияет на активизацию деятельности субъектов предпринимательства (за счет увеличения оборотных средств), поскольку не так остро будет стоять проблема компенсации плательщикам НДС дебетового сальдо.

При начислении НДС в качестве налогооблагаемой базы выступает показатель добавленной стоимости, получаемой как разность между товарной продукцией и стоимостью материальных ценностей, затраченных на производство этой товарной продукции. Такая налогооблагаемая база создает возможность использования различных методов исчисления НДС (при одной и той же заданной ставке). Конечно, указанная политика поставит ряд проблемных вопросов.

Во-первых, после снижения налогов экономика сразу не отреагирует на ослабление налогового пресса. Без сомнения, снижение ставок налогообложения приведет в будущем к увеличению бюджетных поступлений за счет роста предпринимательской активности и расширения базы налогообложения (сейчас 30 \% предприятий убыточны), но для этого необходим определенный временной лаг. В течение этого периода необходимо существенно снижать государственные расходы или увеличивать дефицит бюджета.

Во-вторых, в условиях становления новой экономической системы достаточно важ- но количественно оценить стимулирующие возможности снижения налогов, поскольку в процессе структурных преобразований поведение экономических субъектов существенно изменяется. Отрицательное отношение к бюджетному дефициту не должно означать, что его высокий уровень несовместим с экономическим ростом.

Если в 60-е гг. ХХ столетия бюджетный дефицит был редкостью, то уже в 80-е гг. бюджетные дефициты приняли устойчивый характер. Не стали исключением и 90-е гг., тем более что начало 90-х гг. ознаменовалось глубоким экономическим кризисом, а известно кризис автоматически порождает дефицит бюджета.

Опасным стало проявление бюджетного дефицита в условиях подъема экономики и относительно высокого уровня занятости. Такой дефицит получил название «структурного». Структурный дефицит, в отличие от циклического, не исчезает с переходом экономики в фазу подъема. Именно структурный дефицит и представляет собой серьезную проблему для государственных финансов.

Низкий уровень мобилизации доходов, а также необоснованное в последние годы накопление больших запасов средств на бюджетных счетах, с целью создания финансового резерва, приводили к неравномерности финансирования статей как экономического, так и социального характера.

Причинами значительных остатков объемов финансирования государственного бюджета на счетах бюджетополучателей являются недостатки в планировании и организации бюджетного процесса, задержки в подготовке и принятии нормативно-правовых актов, проведение конкурсных процедур, отсутствие надлежащего контроля со стороны главных распорядителей бюджетных средств за использованием выделенных ресурсов.

Анализ показывает, что социальная направленность бюджетов последних лет определялась преимущественно политико-социальными целями, а бюджетный процесс характеризовался поиском компромисса в распределении средств на социальные программы и экономический рост, порождая дискуссию о приоритетах расходования государ- 
ственных ресурсов. Очевидно, что план расходов ни одного года не выполнялся.

Хотя социальные расходы росли ускоренными темпами, в отдельных случаях их уровень даже не достигает законодательно задекларированных нормативов, а связь между качеством социальных услуг населению и повышением уровня финансирования остается слабой. Это объясняется отсутствием системных реформ в этих отраслях и направлением растущих объемов финансирования образования и здравоохранения, во-первых, на повышение заработной платы работников бюджетной сферы вследствие инфляционных процессов; во-вторых, оплату коммунальных услуг и энергоносителей, цены на которые росли. Такие просчеты указывают на то, что методология прогнозирования имеет серьезные недостатки. Необходим научно обоснованный, подтверждаемый практикой уровень бюджетного планирования и прогнозирования.

\section{Выводы}

Бюджетная политика РФ в среднесрочном периоде должна быть направлена:

- на повышение удельного веса доходов (расходов) федерального и консолидированного бюджета в ВВП;

- повышение удельного веса прямых налогов по отношению к косвенным налогам в период экономического роста экономики;

- снижение ставки налога НДС, которое в будущем приведет к увеличению бюджетных поступлений за счет роста предпринимательской активности и расширения базы налогообложения;

- постепенный переход от системы социальной защиты населения, которая может и не состояться по каким-то причинам, к повышению государственных социальных стандартов и гарантий населению;

- выработку действенного бюджетного механизма, который будет определять новые принципы формирования местных бюджетов, четкое разграничение функций и полномочий всех уровней власти, а отсюда - расходов каждого вида бюджета и, что самое главное, доходов между различными звеньями бюджетной системы.

\section{СПИСОК ЛИТЕРАТУРЫ}

Величко, А. В. Бюджетный механизм инвестирования социальной инфраструктуры / А. В. Величко. - Киев : ИЭ НАН Украины, 1998. - 248 с.

Дробышевский, С. Макроэкономические предпосылки реализации новой модели роста / С. Дробышевский, С. Синельников-Муратов // Вопросы экономики. - 2012. - № 9. - С. 4-24.

Ковалева, Т. М. Бюджет и бюджетная политика в Российской Федерации : учеб. пособие / Т. М. Ковалева, С. В. Барулин. - М. : КНОРУС, 2005. $578 \mathrm{c}$.

Основные направления бюджетной, налоговой, таможенной и тарифной политики на 2019 год и на плановый период 2020 и 2021 годов // Министерство финансов Российской Федерации. - Электрон. текстовые дан. - Режим доступа: http://minfin.ru/ru/ perfomance/budget/federal. - Загл. с экрана.

Основные направления бюджетной, налоговой, таможенной и тарифной политики на 2020 год и на плановый период 2021 и 2022 годов // Министерство финансов Российской Федерации. - Электрон. текстовые дан. - Режим доступа: http://minfin.ru/ru/perfomance/ budget/federal. - Загл. с экрана.

Российский статистический ежегодник : стат. сб. / под ред. А. Е. Суринова ; Росстат. - М. : [б. и.], 2018. - $694 \mathrm{c}$.

Удельный вес доходов и расходов федерального бюджета РФ (по данным Федерального казначейства)за 2001-2007; 2008-2010; 2011-2014 годы. Электрон. текстовые дан. - Режим доступа: http://www.kgs.ru/folder/11192. - Загл. с экрана.

Финансы / В. М. Родионова [и др.]. - М. : Финансы и статистика, 1993. - 400 с.

\section{REFERENCES}

Velichko A.V. Byudzhetnyy mekhanizm investirovaniya sotsialnoy infrastruktury [Budget Mechanism for Investing in Social Infrastructure]. Kiev, IE NAN Ukrainy, 1998. 248 p.

Drobyshevskiy S., Sinelnikov-Muratov S. Makroekonomicheskie predposylki realizatsii novoy modeli rosta [Macroeconomic Background for the Implementation of the New Growth Model]. Voprosy ekonomiki, 2012, no. 9, pp. 4-24.

Kovaleva T.M. Byudzhet i byudzhetnaya politika $v$ Rossiyskoy Federatsii: ucheb. posobie [Budget and Budgetary Policy in the Russian Federation: Study Guide]. Moscow, KNORUS, 2005. 578 p.

Osnovnye napravleniya byudzhetnoy, nalogovoy, tamozhennoy i tarifnoy politiki na 2019 god i na 
A.В. Величко. Проблемы сбалансированности государственного бюджета и экономического роста в РФ

planovyy period 2020 i 2021 godov [Main Directions of the Budget, Tax, Customs and Tariff Policy for 2019 and for the Planning Period of 2020 and 2021]. Ministerstvo finansov Rossiyskoy Federatsii [Ministry of Finance of the Russian Federation]. URL: http://minfin.ru/en/perfomance/ budget/federal.

Osnovnye napravleniya byudzhetnoy, nalogovoy, tamozhennoy i tarifnoy politiki na 2020 god i na planovyy period 2021 i 2022 godov [Main Directions of the Budget, Tax, Customs and Tariff Policy for 2020 and for the Planning Period of 2021 and 2022]. Ministerstvo finansov Rossiyskoy Federatsii [Ministry of Finance of the Russian Federation]. URL: http://minfin.ru/ en/perfomance/budget/federal.
Surinov A.E., ed. Rossiyskiy statisticheskiy ezhegodnik: stat. sb. [Russian Statistical Yearbook. Statistical Compilation]. Moscow, $2018.694 \mathrm{p}$.

Udelnyy ves dokhodov $i$ raskhodov federalnogo byudzheta RF (po dannym Federalnogo kaznacheystva) za 2001-2007; 2008-2010; 2011-2014 gody [Share of Revenues and Expenditures of the Federal Budget of the Russian Federation (According to the Federal Treasury Data) for 2001-2007, 2008-2010, 2011-2014]. URL: http:/www.kgs.ru/folder/ 11192.

Rodionova V.M., Vavilov Yu.Ya., Goncharenko L.I. et al. Finansy [Finance]. Moscow, Finansy i statistika, 1993. $400 \mathrm{p}$.

\section{Information About the Author}

Alexander V. Velichko, Candidate of Sciences (Economics), Associate Professor, Department of Economics and Management, Moscow Aviation Institute, branch "Vzlet", Dobrolyubova St., 5, 416501 Akhtubinsk, RussianFederation, vaw257@mail.ru, https://orcid.org/0000-0003-0080-26630000-0003-0080-2663

\section{Информация об авторе}

Александр Владимирович Величко, кандидат экономических наук, доцент кафедры экономики и управления на предприятии, Филиал «Взлет» МАИ в г. Ахтубинске, ул. Добролюбова, 5, 416501 г. Ахтубинск, Российская Федерация, vaw257@mail.ru, https://orcid.org/0000-0003-0080-2663 